\title{
Geometrical Acoustic Simulation of Open-air Ancient Theatres: Investigation on the Appropriate Objective Parameters for Improved Accuracy
}

\author{
Elena $\mathrm{Bo}^{1}$, Louena Shtrepi ${ }^{1}$, Francesco Aletta ${ }^{2}$, Giuseppina Emma Puglisi ${ }^{1}$, Arianna Astolfi ${ }^{1}$ \\ ${ }^{1}$ Politecnico di Torino, Italy; \\ ${ }^{2}$ University College London, United Kingdom
}

\begin{abstract}
Open-air theatres are considered unconventional environments for acoustic simulations: they usually do not preserve the scenae and are only characterised by the cavea and the orchestra, which lead to very few important reflections. There is still debate on the most suitable parameters to be used for the model calibration according to measured data. In this study the model of the ancient theatre of Syracusae has been simulated with a geometrical acoustic-based software, Odeon (v13.2). In particular this work aims to investigate whether $\mathrm{G}$ (Strength) and DRR (Direct-to-Reverberant Ratio) could be considered as suitable parameters to be used for the calibration of measured data and to test the design of new scenarios.
\end{abstract}

\section{Introduction}

Ancient theatres represent a particular type of environment that has its own specific sound field, which is rather different from the approximated diffuse field within closed spaces. The ongoing research on these environments has shown that already existing objective parameters (ISO 3382-1, 2009) used for indoor spaces do not describe properly the actual acoustic conditions. The ISO 3382-1 standard (2009) room acoustic parameters, such as the Early Decay Time (EDT), Reverberation Time (RT), Clarity $\left(\mathrm{C}_{80}\right)$, and Sound Strength $(\mathrm{G})$ have been used in the European ERATO project (Rindel, 2006). It was shown that since the ISO 3382-1 parameters and temporal decay parameters seem to be less suitable for open-air theatres (Chourmouziadou and Kang, 2008; Farnetani et al., 2008; Iannace et al., 2013; Iannace and Trematerra, 2014; Mo and Wang, 2013). Farnetani et al. (2008) showed how the EDT parameter could not be considered a good descriptor since it is strongly affected by the delay and incidence direction of the first reflections to the receivers. These aspects are related to the position of the sound source. Moreover, also the RT shows different characteristics compared to the common definition used for the description of the indoor environments approximating these spaces according to the classical reverberation theory. Mo and Wang (2013) showed that the conventional RT described in ISO 33821 (2009) which only deals with the sound energy decay rate, is not suitable for evaluating the reverberance of an unroofed space. However, Chourmouziadou et al. (2008) suggested that when comparative studies are performed, RT could be an acceptable compromise.
Based on the recent debate on the topic it emerges that the assessment of the most appropriate acoustic parameters becomes crucial when the reuse of the ancient theatres is considered, since these involves very often also the addition of architectural parts which might substantially vary the acoustics and affect the performance. In these cases, the virtual reconstruction of the theatre, using room acoustics simulation software is a useful approach. Although these methods have been largely validated and their accuracy has been tested through comparisons with measured data, they are still object of continuous research and improvements (Vorländer, 2013). Different Round Robin tests have been performed in order to compare the algorithms of the room acoustic modelling tools (Vorländer, 1995; Bork, 2000; Bork, 2005).

Usually there are three important steps that need to be followed in order to simulate a given environment: (1) adequately simplified geometry modelling; (2) assignment of the material properties of each surface; and (3) appropriate simulation settings. The first and the third step are the result of very strict rules gathered through continuous experiments, while the second step is still affected by the lack of important material databases and on the errors that can be made when trying to describe the acoustical properties by their visual inspection. Therefore, it is evident that this procedure, namely, the calibration of the model, is not trivial for open-air theatres which are made apparently from the same material but affected by different stages of degradation that might not result so evident to a visual inspection. Moreover, the acoustic scattering and diffraction phenomena are more relevant than in closed theatres (Lisa et al., 2004), therefore also the algorithms implemented for these calculations are of great importance (Gade et al., 2005). It was reported that the specific uncertainties that characterise the values of the absorption coefficient $\left(\alpha_{\mathrm{w}}\right)$ and scattering coefficient (s) of materials could affect the accuracy of room acoustic (Vorländer, 2013; ISO, 2003; ISO, 2004). The acoustic parameters are descriptive numerical indexes derived from simulated Impulse Responses (IR) or from energy reflectograms. Therefore, they are strongly affected by the structure of the reflections in an IR. For ancient theatres, the IRs are composed of the direct sound and of two major reflections, which come from the orchestra floor and the scaenae frons (the ancient stage building) (Farnetani et al., 2008). It is obvious that these reflections are strongly affected by the state of conservation of the theatre. Moreover, the configuration of the steps of the cavea are 
of great importance since they are strongly characterized by a high number of scattered reflections (Farnetani et al., 2007). Therefore, the results will be strongly dependent on the geometrical approximations and the scattering algorithm of the geometrical acoustic-based (GA) software, e.g. Odeon (Christensen and Koutsoris, 2015). There are also other simulation wave-based methods that need to be further explored regarding open-air theatres (Lokki et al., 2013). However, most of researchers and practitioners still rely on GA tools and they have to deal with the challenges presented by the ancient theatres: no conventional reverberant field due to the absence of the roof which mainly affects the construction of the late part of the IRs; and presence of shadow zones due to a concave shape and the mirroring surfaces in great lateral areas of the cavea (Lisa et al., 2004), which affect the construction of the early part of the IRs.

As seen, the usage of the GA algorithms on the open-air theatres, as well as the application of the indoor parameters from (ISO-3382-1, 2009), is still matter of continuous discussions and research. The aim of this work is to assess the performance of a predictive software through the evaluation two acoustic parameters, that is Sound Strength (G) and Direct-to-Reverberant Ratio (DRR) from the simulated IRs in the space of an ancient theatre. The ancient theatre of Syracusae (SR) has been considered as a case study. The objective is to give more insight about the relation of the sensitivity of the simulated results to the input parameters, in particular absorption and scattering coefficient assigned to the materials. The SR could be considered a valid archetype model since it is free of contemporary additional structures that might variate its acoustic behaviour. The SR model has been studied in a previous study (Bo et al., 2018), which showed a preliminary benchmark procedure usually performed for indoor environments (Vorländer, 1995; Bork, 2000; Bork, 2005) applied on an ancient open-air theatre. The same methodology has been used also in the present study.

\section{Methods}

A measurement campaign has been performed in the theatre of Syracusae (SR) by the Department of Energy at the Politecnico di Torino, from the 5th to 7th September 2015. The in-situ measurements campaign according to ISO 3382 have been described in detail in Bo et al. (2018). This case study (Figure 1) has Greek origins, dating back to the 5th century BC. It has been later modified by the Romans and has been subject to different damages during the centuries. It is difficult to individuate the original scaenae frons. However, the visible part of the surviving rock-cut cavea can be recognized and measures a diameter of $105 \mathrm{~m}$. The 3D model of SR has been built for Odeon $(\mathrm{O})$, following a few approximations that could not take into account the damages present in the real conditions. The simulation method and algorithms implemented in Odeon have been validated in Round Robin tests (Vorländer, 1995; Bork, 2000; Bork, 2005).

Nowadays, this open-air theatre is intensively used during cyclic summer season festivals in its current (deteriorated) condition, thus it is very important to characterize this space acoustically and to give the possibility to acousticians and designers to make a conscious intervention by adding new temporary elements that could effectively improve the acoustic of the performance. Moreover, the acoustic measurements are made also for conservation purposes. Therefore, this study concerns the "historical acoustics" research field, which is the study of the auditory and acoustic environment of historic sites and monuments (Scarre and Lawson, 2006), with a valorisation purpose. Since it was possible to perform the measurements, also the models have been considered without the presence of the audience.
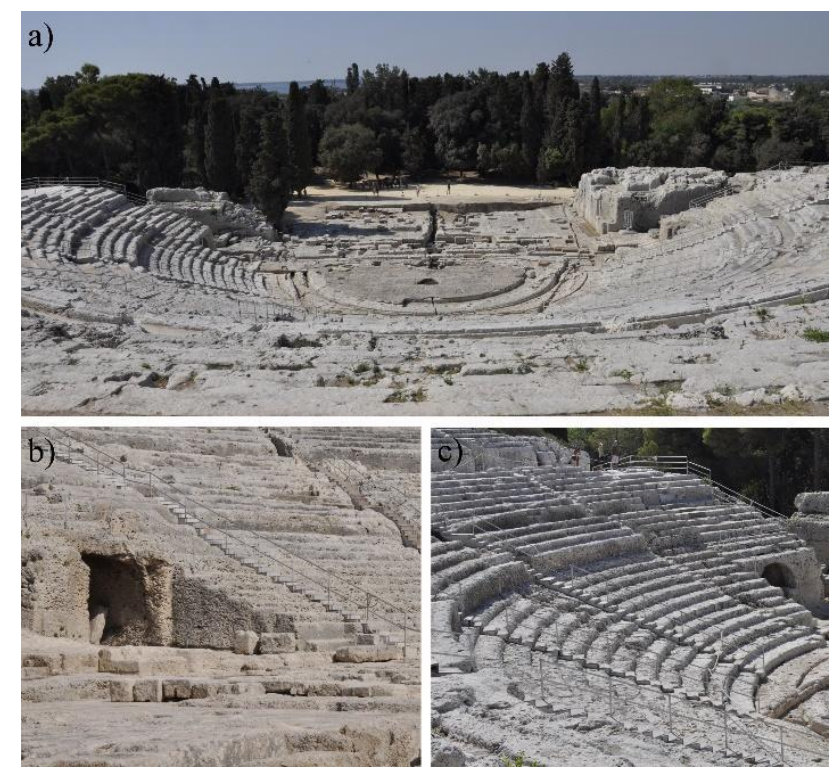

Figure 1: Present conditions of the ancient theatre of Syracusae, whole theatre (a) and cavea details $(\boldsymbol{b}, \boldsymbol{c})$.

\section{Theatre models}

The measurements configuration of microphones and sources has been used also in the simulation model. The comparisons usually require precise input data regarding the acoustic properties of the materials, that is scattering and absorption coefficient. Thus, a more detailed analysis on the effects of the absorption and scattering coefficient variation was proposed.

The SR model has previously been used in different investigations, e.g., simulations concerning its ancient conditions, during the European ERATO project (Rindel, 2006) and in investigations on its contemporary use (Bo, et al., 2015). Figure 2 shows the 3D model configuration, plan and section of SR. Red point in the orchestra (S1) represents the source position. Blue points in the cavea (from 1 to 10) indicate the receiver positions. 


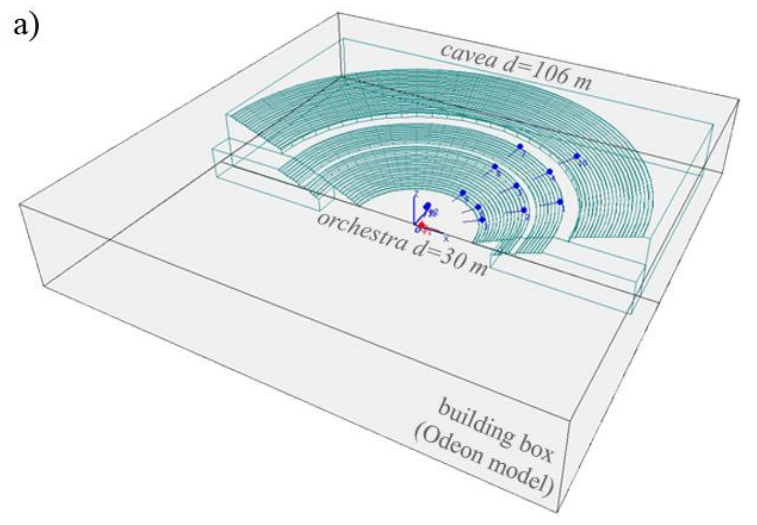

b)
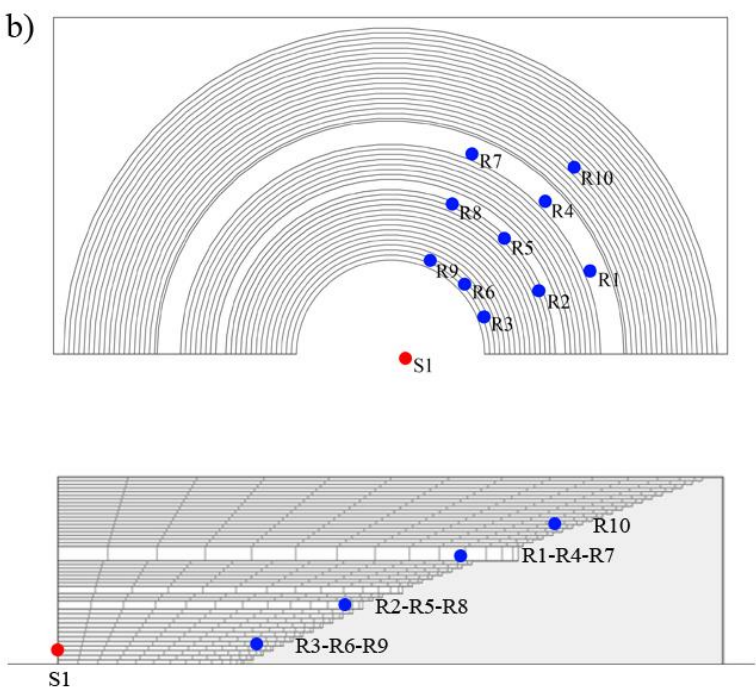

Figure 2: $3 D$ model and source-receiver simulation setup of SR in Odeon (a). Source-receiver set-up is shown, in plan and in section - not at the same scale $(\boldsymbol{b})$.

As in Bo et al. (2018), the following settings have been considered:

- A 100-dB source sound power level, $1500 \mathrm{~ms}$ as the impulse response length, and 4 million rays.

- The Transition Order (TO) in Odeon was limited to 1, since it better resembles the impulse response characteristics in the real condition with only one specular reflection from the stage floor (Christensen and Koutsoris, 2015).

- The environmental data considered in both of the prediction tools were those obtained during the in-situ measurements $\left(\mathrm{t}=33^{\circ} \mathrm{C}, \mathrm{RH}=65 \%\right)$.

Obviously, the aim of acoustical simulations is to obtain predictions that would closely match measured data. In fact, in order to enable a better acoustic design of existing buildings, the simulations first need to replicate the real acoustical conditions of the examined environment. This procedure is considered as the calibration phase of the model and requires a comparison to measured data in the same conditions built in the model.

A well-calibrated model should minimize the perceivable differences between simulation and measurements for any considered acoustic parameter. To achieve this, the material characteristics were adjusted in order to obtain a mean lower difference than the JND (Just Noticeable Difference) of the parameters. Most of the JNDs of the main parameters are given in ISO 3382-1 (2009). The model considered here was calibrated under the testing of twenty alternative materials, with $\alpha_{w}$ equal to $0.05,0.10$, 0.15 , and 0.20 , and with s equal to $0.25,0.40,0.55,0.70$, and 0.85 . The matrix is shown in Table $1: s$ values correspond to a mean value at $500-1000 \mathrm{~Hz}$, while $\alpha_{w}$ is obtained according to the ISO 354 (2003). These variability in the acoustic materials might be considered acceptable since it is based on the possibility of having different degrees of damage on the steps of the cavea. For example, it considers the case of the scattering coefficients of 0.85 (Cox and D'Antonio, 2004), which represents a perfectly preserved periodic triangular section with an angle of $45^{\circ}$, and a scattering of 0.25 , which refers to a heavily damaged cavea.

Table 1: Absorption ( $\left.\alpha_{w}\right)$ and scattering $(s)$ coefficients used to characterise the materials chosen for the cavea in 20 combinations, i.e. four scattering alternatives for each absorption coefficient.

\begin{tabular}{|c|c|c|c|c|c|}
\hline Variable & \multicolumn{5}{|c|}{ Values } \\
\hline$s[-]$ & 0.25 & 0.40 & 0.55 & 0.70 & 0.85 \\
\hline \multirow{3}{*}{$\alpha_{w}[-]$} & 0.05 & 0.05 & 0.05 & 0.05 & 0.05 \\
\cline { 2 - 6 } & 0.10 & 0.10 & 0.10 & 0.10 & 0.10 \\
\cline { 2 - 6 } & 0.15 & 0.15 & 0.15 & 0.15 & 0.15 \\
\cline { 2 - 6 } & 0.20 & 0.20 & 0.20 & 0.20 & 0.20 \\
\hline
\end{tabular}

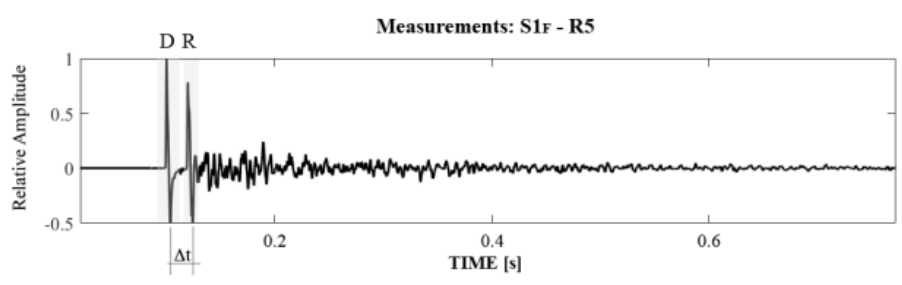

Odeon: S1 - R5

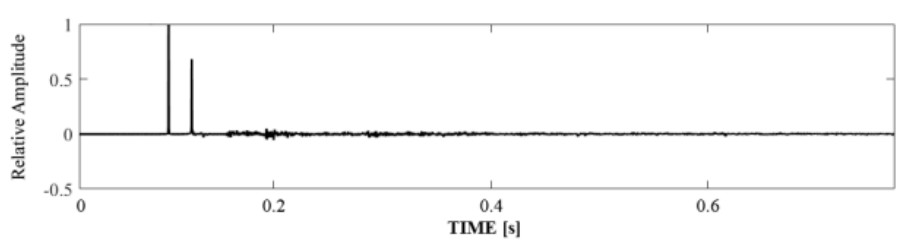

Figure 3: Measured IR in SR for R5 position (a), and corresponding IRs simulated with Odeon $(\boldsymbol{b})$.

\section{Parameters}

A careful analysis of the typical impulse response measured in the SR theatre shows that beyond the direct sound and the strong reflection from the orchestra floor, minor early and late energy contributions from sound diffusion are observed (Figure 3). This texture could be observed also in the simulated impulse responses.

Based on the approximations of the algorithms implemented in Odeon, more generally in GA-based software, the prediction of the early reflections is based on a deterministic method (namely image sources method), while the sound tail is generally based on a 
stochastic approach (namely ray-tracing method), which closely depends on the specific scattering and diffraction algorithms. The simulation of open-air spaces is thus affected by uncertainties due to the settings of these two properties. As reported also in the previous section, for this reason, more insight is needed, especially in controlling the boundary conditions and input data for better matching the measurements results. Since it is difficult to have a high accuracy in the comparisons performed through a visual inspection of the overlapping of the simulated and measured IRs, the use of objective measures might be a useful and practical alternative. However, most of the usually adopted room acoustical parameters do not suit the unconventional acoustic sound field of these theatres and might not be informing properly the calibration and design processes (Chourmouziadou and Kang, 2008; Farnetani et al., 2008; Iannace, Trematerra and Masullo, 2013; Iannace and Trematerra, 2014; Mo and Wang, 2013). This study focuses on two simulated objective parameters - i.e. Sound Strength $(G)$ and Direct-to-Reverberant-Ratio (DRR). While $G$ is widely considered as one of the most reliable parameters in open-air theatres characterization, the DRR is newly introduced.

Sound Strength, $\mathrm{G},(\mathrm{dB})$ is the logarithmic ratio of the measured sound energy (i.e., the squared and integrated sound pressure) to the sound energy that would arise in a free field at a distance of $10 \mathrm{~m}$ from a calibrated omnidirectional sound source. The Equations (1) is given in ISO 3382-1 (2009) - specified then by (2) and (3) - as well as its JND, which equals $1 \mathrm{~dB}$.

$$
G=10 \log \frac{\int_{0}^{\infty} p^{2}(t) d t}{\int_{0}^{\infty} p_{10}^{2}(t) d t}=L_{p E}-L_{p E, 10}
$$

in which

$$
L_{p E}=10 \lg \left[\frac{1}{T_{0}} \int_{0}^{\infty} \frac{p^{2}(t) d t}{p_{0}^{2}}\right]
$$

and

$$
L_{p E, 10}=10 \lg \left[\frac{1}{T_{0}} \int_{0}^{\infty} \frac{p_{10}^{2}(t) d t}{p_{0}^{2}}\right]
$$

where

$-p(t)$ is the instantaneous sound pressure of the impulse response measured at the measurement point;

$-p_{10}(t)$ is the instantaneous sound pressure of the impulse response measured at a distance of $10 \mathrm{~m}$ in a free field;

$-\mathrm{L}_{\mathrm{pE}}(\mathrm{dB})$ is the sound exposure level of $\mathrm{p}(\mathrm{t})$;

$-\mathrm{L}_{\mathrm{pE}, 10}(\mathrm{~dB})$ is the sound exposure level of $\mathrm{p}_{10}(\mathrm{t})$;

$-\mathrm{p}_{0}$ is the reference sound pressure of $20 \mu \mathrm{Pa}$;

$-\mathrm{T}_{0}$ is the reference time interval of $1 \mathrm{~s}$.

In the above equations, $t=0$ corresponds to the start of the direct sound, i.e. which corresponds to the arrival of the direct sound at the receiver, and $\infty$ should correspond to a time that is greater than or equal to the point at which the decay curve has decreased by $30 \mathrm{~dB}$.

$\mathrm{G}$ requires a calibration procedure for the sound power of the source. Different procedures have been described in the ISO 3382-1 standard. Further details on the measurement procedure and calibration for $\mathrm{G}$ can be found in Bo et al. (2018).

Direct-to-reverberant ratio, DRR, which corresponds to the comparison between the ratio of the energy between the direct peak (D) and the reflections (energetic component of the IR shown in Figure 3). DRR is defined by the following Equation (4):

$$
D R R \equiv 10 \log \frac{\int_{0}^{\tau} h^{2}(\tau) d \tau}{\int_{\tau}^{\infty} h^{2}(\tau) d \tau}
$$

where

- $\mathrm{h}(\mathrm{n})$ is the IR samples between two positions;

- $\tau$ is the chosen time that separates the direct sound from all the reflections in the IR (typically $2-3 \mathrm{~ms}$ ).

The interval between direct and reflected sound is indicated as $\Delta \mathrm{t}$ in Figure 3. As noticeable, in case of absence of scaenae frons, the main reflected contribution is given by the floor.

This parameter was chosen because for open-air theatres spaciousness is a fundamental component of the listening experience. In fact, DRR is considered an important cue for sound source distance judgments: in absence of sound reflections, distance is confounded with intensity at the ear. This means that, without reflections, is nearly impossible to assess the distance of a sound source from a receiver. There have been few researches regarding this parameter. However, it is still under study. The definition of the JND for this parameter has been object of different studies. The earliest contributions were proposed in the late 1960's, by Reichardt and Schmidt (1966) and Reichardt and Schmidt (1967), who explored spatial impression by examining the importance of reflections from well-defined directions between the direct and reverberant sound fields. In a "fully anechoic" environment, JND was established as $2 \mathrm{~dB}$ (with DRR equal to $0 \mathrm{~dB}$ ).

Zahorik (2002) used acoustic simulations to assess the

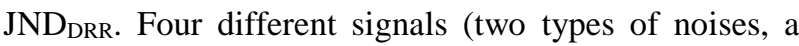
speech, and an impulse) were used, varying the overall intensity level of the signals, and this was the main difference with the previous study. In this case, the results showed roughly constant JNDs of $5-6 \mathrm{~dB}$ (with DRRs equals to 0,10 , and $20 \mathrm{~dB}$ ).

Finally, Larsen et al. (2008), conducted psychophysical experiments where a wideband noise was employed to determinate the JND (with DRRs equals to $-10,0,10$ and $20 \mathrm{~dB}$ ), taking into consideration also spectral cues. This allowed determining a higher sensitivity at 0 and $10 \mathrm{~dB}$ DRR, with JND of $2-3 \mathrm{~dB}$, while a much lower sensitivity at -10 and $20 \mathrm{~dB}$ DRR. This result confirmed the aforementioned Reichardt and Schmidt findings.

Since in the case of open-air theatre, the first reflection is quite similar to the direct sound, we expect DRR values around 0 . Thus, in this work the assumed JND is $2 \mathrm{~dB}$.

All the simulated IRs have been exported in wav format from both software and have been analysed by means of 
the same tool, i.e. Aurora, version 4.4, regarding the estimation of the $\mathrm{G}$ values. While, the DRR values have been assessed by an in-house script implemented by the authors.

a) G

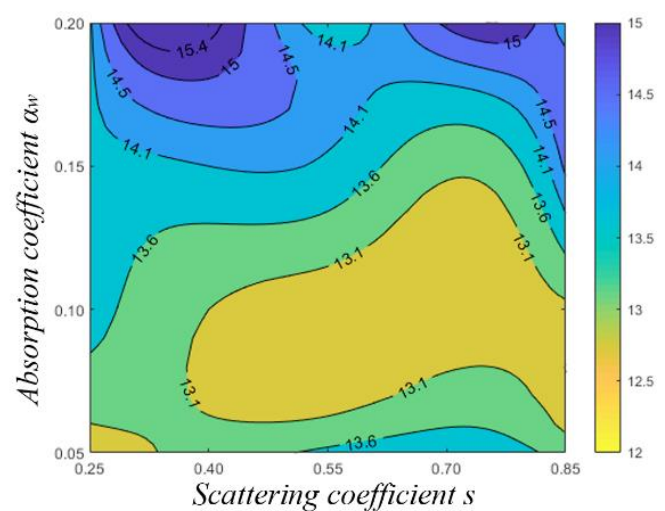

b)

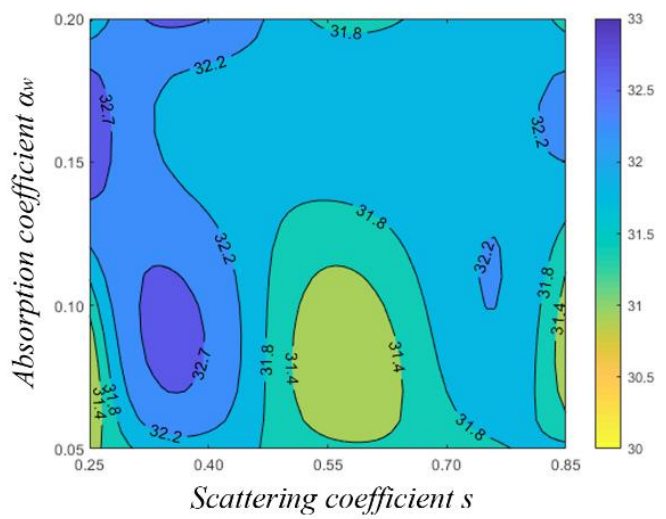

Figure 4: Sum of Absolute Differences (SAD) between the measured and simulated values over all the receivers for $G$ values (a), averaged between $500 \mathrm{~Hz}$ and $1 \mathrm{kHz}$, and broadband DRR $(\boldsymbol{b})$.

\section{Results}

The behaviour of the two simulated parameters was observed in Odeon and compared to measured results. Twenty material alternatives - obtained through the variation of absorption and scattering coefficients, $\alpha$ and $\mathrm{s}-$ were tested in order to explore potential differences. This process offered new insights into the sensitivity of the simulation tools to the variation of the input variables $\alpha_{w}$ and $s$ values of the cavea' surface and its variations. The differences for all the receivers between the measured and simulated results are shown in Figure 4 for 20 alternative combinations of absorption and scattering. The iso-level curves shown in Figure 4 were based on SAD, in decibels. i.e., the Sum of the Absolute Differences between the simulated values, $\mathrm{s}_{\mathrm{n}}$, and the measured ones, $\mathrm{m}_{\mathrm{n}}$, for each receiver, expressed by Equation (5) (Li, Ding and Zhang, 2011), were $\mathrm{n}$ is equal to the number of receivers in the theatre:

$$
S A D=\sum_{1}^{n}\left|s_{n}-m_{n}\right|
$$

The lowest is the SAD the better is the agreement between simulated and measured values. The curves have been obtained by a two-dimensional data interpolation using the MATLAB function "interp2" with the "spline" method active. This method was chosen in order to have smooth first and second derivatives throughout the curves. Figures $4 \mathrm{a}$ and $4 \mathrm{~b}$, refer to parameter $\mathrm{G}$ and DRR, respectively. The light-yellow colour in the graphs shows the $\alpha_{\mathrm{w}}$ and s combinations for which the simulated values were closest to the measured ones.

The results show that depending on which parameter is considered, the best agreement between the simulated and measured values could not be obtained for the same combination of $\alpha_{\mathrm{w}}$ and s. For $\mathrm{G}$, the best matching between measured and simulated values occurs with low absorption values over the whole range of scattering coefficients $(s \geq 0.40)$. In the case of DRR the best calibration values are also for low values of $\alpha_{\mathrm{w}}$ and $\mathrm{s}$ in the range $0.50-0.65$.However, both parameters show an agreement that is obtained in a range around the values of $\alpha_{\mathrm{w}}=0.10$ and $\mathrm{s}=0.55$. Thus, this combination was considered useful for the calibration of the model.

Table 2: Mean values of the measured $(M)$ and simulated (S) $G$ and DRR for the source in position $S 1$. The simulated models are calibrated with $\alpha_{w}=0.1$ and $s=0.55$. The values that differ more than 1 JND from the measured values are in bold.

\begin{tabular}{|c|c|c|c|c|c|}
\hline \multirow{2}{*}{ Row } & \multirow{2}{*}{ Rec } & \multicolumn{2}{|c|}{ DRR (dB) } & \multicolumn{2}{|c|}{ G (dB) } \\
\cline { 2 - 6 } & & $\mathbf{M}$ & $\mathbf{S}$ & $\mathbf{M}$ & $\mathbf{S}$ \\
\hline \multirow{2}{*}{$\begin{array}{c}\text { First } \\
\text { row }\end{array}$} & $\mathrm{R} 3$ & 1.7 & 0.5 & -0.3 & -1.7 \\
\cline { 2 - 6 } & $\mathrm{R} 6$ & 4.6 & 4.7 & -0.9 & -2.3 \\
\cline { 2 - 6 } & $\mathrm{R} 9$ & 3.4 & -0.3 & -2.5 & -1.8 \\
\hline $\begin{array}{c}\text { spatial } \\
\text { mean }\end{array}$ & & 3.2 & 1.6 & -1.2 & -1.9 \\
\hline \multirow{2}{*}{$\begin{array}{c}\text { Second } \\
\text { row }\end{array}$} & $\mathrm{R} 2$ & -3.2 & 1.9 & -4.8 & -6.7 \\
\cline { 2 - 6 } & $\mathrm{R} 5$ & -2.4 & 1.7 & -5.4 & -7.1 \\
\cline { 2 - 6 } & $\mathrm{R} 8$ & -2.4 & 1.5 & -6.0 & -7.0 \\
\hline \multirow{2}{*}{$\begin{array}{c}\text { spatial } \\
\text { mean }\end{array}$} & & -2.7 & $\mathbf{1 . 7}$ & -5.4 & $-\mathbf{6 . 9}$ \\
\hline \multirow{2}{*}{$\begin{array}{c}\text { Third } \\
\text { row }\end{array}$} & $\mathrm{R} 1$ & -2.5 & 2.2 & -7.8 & -9.0 \\
\cline { 2 - 6 } & $\mathrm{R} 4$ & -2.1 & 2.0 & -8.0 & -9.8 \\
\cline { 2 - 6 } & $\mathrm{R} 7$ & -0.2 & 1.9 & -9.3 & -9.8 \\
\hline \multirow{2}{*}{$\begin{array}{c}\text { spatial } \\
\text { mean }\end{array}$} & & -1.6 & $\mathbf{2 . 0}$ & -8.4 & $\mathbf{- 9 . 5}$ \\
\hline $\begin{array}{c}\text { Last } \\
\text { row }\end{array}$ & $\mathrm{R} 10$ & -0.1 & $\mathbf{2 . 1}$ & -10.2 & $\mathbf{- 1 1 . 4}$ \\
\hline
\end{tabular}

Table 2 shows all the measured values and the simulated ones of $G$ and DRR for the calibrated model of SR. The $G$ values are averaged over the central $500 \mathrm{~Hz}$ and $1 \mathrm{kHz}$ octave-band frequencies and spatial values have been added for each row. The DRR values are broadband, and again spatial values have been added for each row.

For both $\mathrm{G}$ and DRR, the differences between the average simulated values for each row are always within or quite close the JND compared to measured values.

A good agreement has been shown between the results as can be seen from the graph in Figure 5, where the average $\mathrm{G}$ for each row is represented along the average distance 
from the source, in the cases of measurements and simulations. As already shown in Bo et al. (2018), the software correctly simulates the reduction of $G$ with the distance from the source, with slopes in $\mathrm{dB}$ per distance doubling $(\mathrm{dB} / \mathrm{dd})$ that is $6.6 \mathrm{~dB} / \mathrm{dd}$ compared to $6.3 \mathrm{~dB} / \mathrm{dd}$ for the measurements.

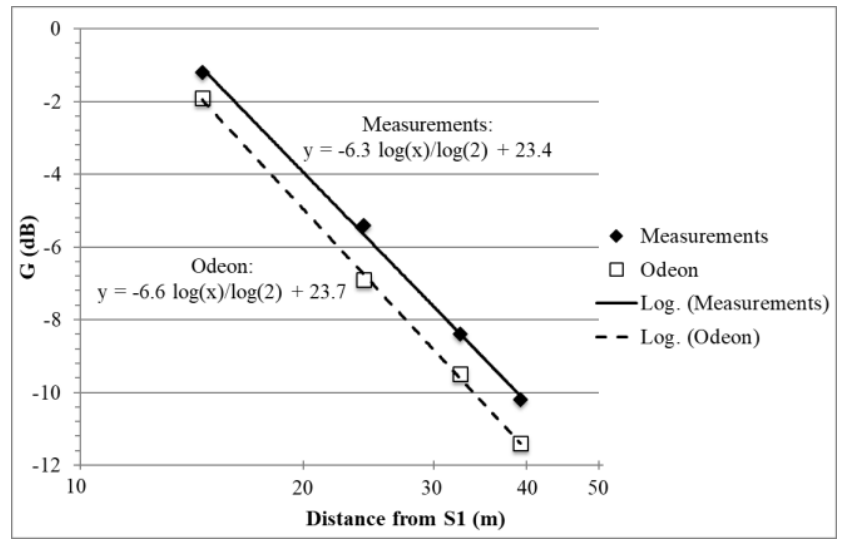

Figure 5: G values averaged over $500 \mathrm{~Hz}$ and $1 \mathrm{kHz}$ octave-band frequencies, and for each row, represented along the average distance from the source.

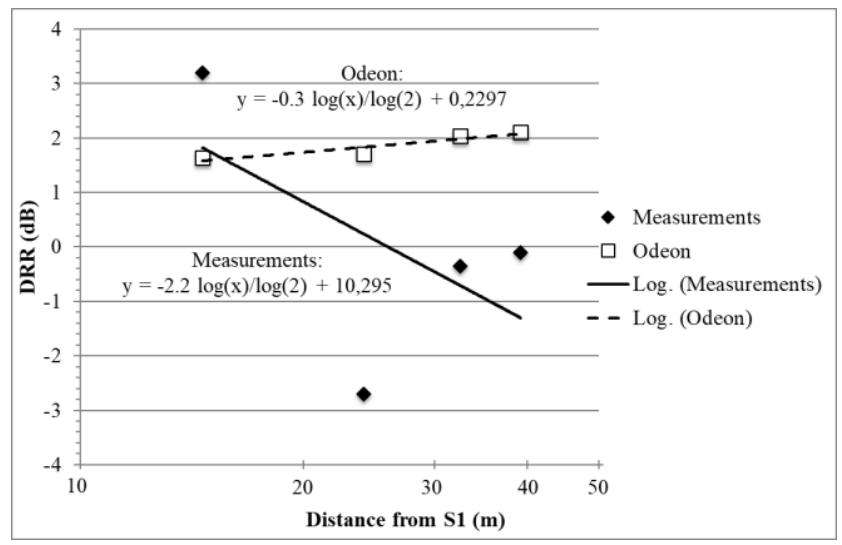

Figure 6: Broadband DRR values averaged for each row, represented along the average distance from the source.

In Figure 6, the average DRR for each row is also represented along the average distance from the source S1. The results show that the DRR has a different trend for the simulations and measurements. For the simulations, the values are almost constant with the distance from the source, i.e. almost within the JND limit of $2 \mathrm{~dB}$. On the other side, measured values state a very different behaviour, which underline a prevalence of the direct sound in the first rows that is overcame by the reflected sound at the second and third rows, and reach a balance very far from the source, at the fourth row. The reason could be the presence of the reflected energy that is scattered from the cavea and that contribute to the increase in the reflected sound of the second and third rows. This result highlights the importance of the DRR parameter in the calibration process. Moreover, it suggests further possible variations of the geometrical model in order to calibrate the reflections with respect to the direct sound. This modifications will be addressed in the future to test the sensitivity of the software with respect to the model geometrical approximations.

\section{Discussion and conclusions}

This paper dealt with the investigation in the use of a GAbased software, Odeon, in the simulation of two parameters, Strength (G) and Direct-to-Reverberant Ratio (DRR) in an ancient open-air theatre. It was shown that there is a number of limitations in the methodological approach implemented in the present study, which are mainly related to the actual applicability of the ISO 33821 (2009), intended for roofed performance spaces, to open-air environments. This has been highlighted also in the previous study that dealt with other ISO parameters.

The major drawback, for the state of the art of GA modelling software, is that the different simulation tools require different input data (Lam, 1996). In practice, the absorption and scattering coefficient values are calibrated, i.e. varied within the range of their measurement uncertainty, in order to match the simulation results to the measured values. This may result in different values of these coefficients for different software. However, the methodology showed here, demonstrated that the accuracy of GA software can be improved and that the results could be suitable when the aim is to investigate design alternatives, given an accurate calibration of the initial model.

A lower sensitivity is indicated for Odeon software, as visible from Figure 4 for both $G$ and DRR results. Both software parameters lead towards the same combination of absorption and scattering, which is $\alpha_{w}=0.10$ and $s=$ 0.55 , and thus this combination can be considered for the calibration of the model and further design alternatives can be tested. The good matching between measured and calculated values for $\mathrm{G}$ along the distance from the source confirm the correct choice of the initial parameters. From the current choice of $\alpha_{w}=0.10$ and $s=0.55$, the DRR was found to be less variable with the distance. This was not encountered in the measurements which showed a different trend. This suggested that further possible approximations on the geometrical construction of the model could be tested in order to balance the reflections with respect to the direct sound.

Future studies will consider different simulation settings and different software to compare measured and simulated data. Subjective tests will be also conducted, which will suggest the most reliable parameter for openair theatres simulations. Other ISO 3382-1 quantities will be also considered for the calibration, such as Clarity C50 end Early Decay Time, as well as binaural parameters that are not included in the standard but that can be object of future investigation.

\section{Acknowledgement}

This work was supported through a Ph.D. scholarship awarded to the first author by the Politecnico di Torino 
(Turin, Italy). A special mention is deserved to the contributions of Monika Rycháriková and David Pelegrín-Garcia - KU Leuven Laboratory of Soft Matter and Biophysics - who participated actively to the research during these years.

\section{References}

Bo, E., Astolfi, A., Pellegrino, A., Pelegrín-Garcia, D., Puglisi, G.E., Shtrepi, L., and Rychtarikova, M. (2015). The modern use of ancient theatres related to acoustic and lighting requirements: Stage design guidelines for the Greek theatre of Syracuse. Energy build. 95, 106-115.

Bo, E., Shtrepi, L., Pelegrín-Garcia, D., Barbato, G., Aletta, F., and Astolfi, A. (2018). The Accuracy of Predicted Acoustical Parameters in Ancient Open-Air Theatres: A Case Study in Syracusae. Appl. Sci. 8, 1393, 1-22.

Bork, I (2000). A comparison of room simulation software - the $2^{\text {nd }}$ Round Robin on Room Acoustical Computer Simulations. Acta Acust. United Acust. 86, 943-946.

Bork, I (2005). Report on the $3^{\text {rd }}$ Round Robin on Room Acoustical Computer Simulation - Part II: Calculations. Acta Acust. United Acust. 91, 753-763.

Chourmouziadou, K. and Kang J. (2008). Acoustic evolution of ancient Greek and Roman theatres. Appl. Acoust. 69, 514-529.

Christensen, C. L., and Koutsouris, G. (2015). Odeon Room acoustics Software. Version 13. Full User's Manual. Odeon A/S, Lyngby (DNK). Available online: https://www.odeon.dk/ (accessed on 10 January 2015).

Cox, T.J., D'Antonio, P. (2004). Acoustic Absorbers and Diffusers: Theory, Design and Application. Spon, New York (USA).

Farnetani, A., Prodi, N., and Pompoli, R. (2007). Measurements of the sound scattering of the steps of the cavea in ancient open-air theatres. Proocedings of the International Symposium of Room Acoustics. Seville (ESP), 10-12 September 2007

Farnetani, A., Prodi, N. and Pompoli, R. (2008). On the acoustics of ancient Greek and Roman theatres. $J$. Acoust. Soc. Am. 124, 157-167

Gade, A.C., Lynge, C., Lisa, M., and Rindel, J.H. (2005). Matching simulations with measured acoustic data from Roman theatres using Odeon program. Proocedings of the Forum Acusticum. Budapest (HUN), 29 August - 2 September 2005.

Iannace, G., Trematerra, A., and Masullo M. (2013). The large theatre of Pompeii: Acoustic evolution. Build. Acoust. 20, 215-227

Iannace, G., and Trematerra, A. (2014). The rediscovery of Benevento Roman theatre acoustics. J. Cult. Herit. 15, 698-703.

International Organisation for Standardisation (2003).
Acoustics - Measurements of Sound Absorption in a Reverberant Room (ISO 354).

International Organisation for Standardisation (2004).

Acoustics - Sound Scattering Properties of Surface Part 1: Measurements of the Random-Incidence Scattering Coefficient in a Reverberation Room (ISO 17497).

International Organisation for Standardisation (2009).

Measurements of Room Acoustic Parameters - Part 1: Performance spaces (ISO 3382-1).

Larsen, E., Iyer, N., Lansing, C. R., and Feng, A. S. (2008). On the minimum audible difference in directto-reverberant energy ratio. J. Acoust. Soc. Am., 1(124), 450-461

Lam, Y.W. (1996). A comparison of three diffuse reflection modeling methods used in room acoustics computer models. J. Acoust. Soc. Am. 100, 2181-2192

Li, Z., Ding, Q., Zhang, W. (2011). A Comparative Study of Different Distances for Similarity Estimation. In Intelligent computing and Information Science; Chen, R, Ed.; Communications in Computer and Information Science. Springer, Berlin/Heidelberg (GE), Volume 134.

Lisa, M., Rindel, J.H. and Christensen, C.L. (2004). Predicting the acoustics of open-air theatres: The importance of calculation methods and geometrical details. Proocedings of the Baltic-Nordic Acoustics Meeting. Mariehamn, Aland (FI), 8-10 June 2004.

Lokki, T., Southern, A., Siltanen, S., Savioja, L. (2013). Acoustics of Epidaurus - Studies With Room Acoustics Modelling Methods, Acta Acustica inited with Acustica 99 (1), 40-47.

Mo, F. and Wang. J. (2013). The conventional RT is Not Applicable for Testing the Acoustical Quality of Unroofed Theatres. Build. Acoust. 20, 81-86.

Reichardt, W. and Schmidt, W (1966). Die horbaren stufen des raumeindruckes bei musik - The audible steps of spatial impression in music performances. Acta Acustica 17

Reichardt, W. and Schmidt, W. (1967). The detectability of changes in sound field parameters for music. Acustica 18, 247-282

Rindel, J.H. (2006). ERATO; Final Report. INCO-MED Project, ICA3-CT-2002-10031. Lyngby (DNK)

Scarre, C., and Lawson, G. (2006). Archaeoacoustics. Mc Donald Institute for Archaeological Research, University of Cambridge (UK).

Shtrepi, L., Astolfi, A., Pelzer, S., Vitale, R. and Rychtarikova, M. (2015). Objective and perceptual assessment of the scattered sound field in a simulated concert hall. J. Acoust. Soc. Am. 138, 1485-1497.

Vorländer, M. (1995). International round robin on room acoustical computer simulations. Proocedings from 15 ${ }^{\text {th }}$ ICA: International Congress on Acoustics. Trondheim (NO), 26-30 June 1995. 
Vorländer, M. (2013). Computer simulations in room acoustics: Concepts and uncertainties. J. Acoust. Soc. Am. 133, 1203-1213.

Zahorik, P. (2002). Direct-to-reverberant energy ratio sensitivity. J. Acoust. Soc. Am. 112, 2110-2117. 